\title{
The Effect of Chronic Doxorubicin Treatment on Mitogen-Activated Protein Kinases and Heat Stress Proteins in Rat Hearts
}

\author{
P. ŠIMONČÍKOVÁ, T. RAVINGEROVÁ, M. BARANČíK
}

Institute for Heart Research, Centre of Excellence for Cardiovascular Research, Slovak Academy of Sciences, Bratislava, Slovak Republic

Received January 25, 2008

Accepted March 25, 2008

On-line March 28, 2008

\section{Summary}

The study has been designed to characterize protein systems involved in the responses of rat hearts to chronic doxorubicin (DOX) treatment. We investigated the influence of DOX on cardiac function, mitogen-activated protein kinases (MAPKs) and heat stress proteins (HSPs). Doxorubicin was administered to rats by intraperitoneal injections over a period of 6 weeks. In control and DOX-treated hearts exposed to 20 min global ischemia and $40 \mathrm{~min}$ reperfusion the recovery of contractile function after ischemia/reperfusion (I/R) was determined. The levels and phosphorylation state of proteins in tissue samples were analyzed using specific antibodies. We found an activation of extracellular signal-regulated kinases (ERKs) in rat hearts exposed to DOX treatment and better recovery of contractile function after I/R. Analysis of HSPs showed that DOX induced up-regulation of the levels of HSP60 and down-regulation of HSP70 levels. The levels and/or specific phosphorylation of other studied proteins (p38MAPK, HSP27, HSP90) were not influenced by DOX. The results point to the possible role of ERKs and some HSPs in mechanisms underlying the response of rat hearts to chronic DOX treatment.

\section{Key words}

Doxorubicin $\bullet$ MAPK $\bullet$ Heat stress proteins $\bullet$ Heart

\section{Corresponding author}

M. Barančík, Institute for Heart Research, Slovak Academy of Sciences, Dúbravská cesta 9, P.O. Box 104, 84005 Bratislava, Slovak Republic. Fax: +421 25477 6637. E-mail: usrdmiro@savba.sk

\section{Introduction}

Doxorubicin (DOX) is a type of anti-cancer drug, the clinical use of which is limited by serious adverse effects including cardiotoxicity. These cardiotoxic effects result in cardiac dysfunction and finally congestive heart failure (Mettler et al. 1977, Ferrans 1978). Doxorubicin also blocks the cell cycle and induces apoptosis but the mechanisms of myocardial impairment remain uncertain (Wang et al. 2004). Several changes may play a role in the pathogenesis of cardiomyopathy induced by DOX. The list includes inhibition of nucleic acid and protein synthesis, release of vasoactive amines, changes in adrenergic function, abnormalities in the mitochondria, lysosomal alterations, altered sarcolemmal $\mathrm{Ca}^{2+}$ transport, imbalance of myocardial electrolytes (Singal et al. 1987). Moreover, oxidative stress due to overproduction of free radicals and antioxidant-deficit plays an important role in development of DOX cardiomyopathy (Thornalley and Dodd 1985).

Mitogen-activated protein kinase (MAPK) signaling pathways are the primary intermediators of induction of apoptosis by oxidative stress. There are three major MAPK cascades, including extracellular signalregulated kinases $\left(\mathrm{ERK}_{\mathrm{S}}\right)$, p38-MAPK and c-Jun NH2terminal kinases/stress-activated protein kinases $\left(\mathrm{JNK}_{\mathrm{S}} / \mathrm{SAPK}_{\mathrm{S}}\right)$. In the cardiovascular system, ERKs are activated by growth factors, cytokines etc. thereby mediating cell survival as well as offer cytoprotection (Sugden and Bogoyevitch 1995, Wang et al. 1998). In contrast, JNKs and p38-MAPKs are activated by cellular stresses, including oxidative stress, and are thought to correlate with cardiomyocyte apoptosis and cardiac 
pathologies (Kyriakis and Avruch 1996). We have shown previously that MAPKs, especially ERKs play a role in responses of rat hearts to pathological situations (Strnisková et al. 2003, Barančík et al. 2007). There is also a link between MAPKs and heat stress proteins (HSPs) (Dou et al. 2005). HSPs as molecular chaperones play an important role in protein-protein interactions, such as folding and assisting in the establishment of proper protein conformation. These proteins appear to have a significant role in responses and adaptation of myocardium to stress but the role of HSPs in modulation of cardiomyopathy induced by DOX is not yet clear.

The current study investigated the involvement of MAPKs and heat-stress proteins in the responses of rat hearts to chronic doxorubicin treatment.

\section{Methods}

\section{Experimental model}

Male Wistar rats were divided into two groups. The first group served as a control and animals were treated with saline. In the second group, doxorubicin was administered to rats by intraperitoneal injections over a period of 6 weeks (cumulative dose $15 \mathrm{mg} / \mathrm{kg}$ ). All animals were housed at a temperature of $22-24{ }^{\circ} \mathrm{C}$ in individual cages and fed a regular pellet diet ad libitum. After 6 weeks the animals were anaesthetized with sodium pentobarbitone $(40 \mathrm{mg} / \mathrm{kg}$, i.p.), heparinized (500 IU) and sacrificed by cervical dislocation. The investigation conformed with the Guide for the Care and Use of Laboratory Animals published by the US National Institutes of Health (NIH Publication No 8523, revised 1996).

\section{Perfusion technique}

The hearts were rapidly excised, placed in icecold perfusion buffer, cannulated via the aorta and placed into the Langendorff system for perfusion at a constant pressure of $70 \mathrm{~mm} \mathrm{Hg}$ and at $37{ }^{\circ} \mathrm{C}$. Perfusion solution was a modified Krebs-Henseleit buffer gassed with $95 \% \mathrm{O}_{2}$ and $5 \% \mathrm{CO}_{2}$ (pH 7.4) containing (in mmol/l): $\mathrm{NaCl} 118.0, \mathrm{KCl} 3.2, \mathrm{MgSO}_{4}$ 1.2, $\mathrm{NaHCO}_{3}$ 25.0, $\mathrm{KH}_{2} \mathrm{PO}_{4} 1.18, \mathrm{CaCl}_{2}$ 2.5, glucose 7.0. Left ventricular pressure was measured by means of a latex water-filled balloon inserted into the left ventricle via the left atrium (adjusted to obtain end-diastolic pressure of 5-7 $\mathrm{mm} \mathrm{Hg}$ ) and connected to a pressure transducer (P23 Db model, Gould Statham Instruments, USA). Maximal rates of pressure development and fall, $+\mathrm{dP} / \mathrm{dtmax}$ and
$-\mathrm{dP} / \mathrm{dtmax}$, as the indexes of contraction and relaxation were monitored during stabilization and pre-ischemia period and were continuously recorded until the end of reperfusion. Recovery of contractile function after $I / R$ was expressed as percentage of preischemic baseline values.

\section{Protocol of experimental ischemia}

The Langendorff-perfused hearts were allowed to stabilize $(20 \mathrm{~min})$ before further interventions. The hearts were then exposed to $20 \mathrm{~min}$ global ischemia induced by stop of aortal inflow and 40 min reperfusion.

\section{Preparation of tissue protein fractions}

The tissue samples were obtained from salinetreated and DOX-treated rats at the end of the application period. The tissues from left ventricle were wiped in liquid nitrogen, resuspended in ice-cold buffer $\mathrm{A}$ containing (in $\mathrm{mmol} / \mathrm{l}$ ): 20 Tris- $\mathrm{HCl}, 250$ sucrose, 1.0 EGTA, 1.0 dithiothreitol (DTT), 1.0 phenylmethylsulfonylfluoride (PMSF) and 0.5 sodium orthovanadate ( $\mathrm{pH}$ 7.4) and homogenized with a Teflon glass homogenizer. The homogenates were centrifuged at $700 \mathrm{x} \mathrm{g}$ for $5 \mathrm{~min}$ at $4{ }^{\circ} \mathrm{C}$, pellets after this centrifugation were discarded and the supernatants were centrifuged again at $13,600 \mathrm{xg}$ for $30 \mathrm{~min}$. The postmitochondrial supernatants after this second centrifugation, termed as soluble fractions, were used for further analysis. The protein concentrations were estimated by the method of Bradford (1976).

Electrophoresis and immunochemical Western blot analysis

Samples of protein fractions containing equivalent amounts of proteins per lane were separated by SDS-PAGE. For Western blot assays, proteins after electrophoretic separation were transferred to nitrocellulose membrane. For primary immunodetection were used antibodies specific against the following proteins: p38-MAPK, ERK, GAPDH (all from Santa Cruz Biotechnology), phospho-p38-MAPK (Thr180/ Tyr182), phospho-ERK (Thr202/Tyr204), phosphoHSP27 (Ser82), Hsp90 (all from Cell Signaling Biotechnology), HSP60, HSP70 (both from Sigma). Peroxidase-labeled anti-rabbit or anti-mouse imunoglobulins (Amersham Biosciences) were used as the secondary antibodies. Bound antibodies were detected by the ECL method. 


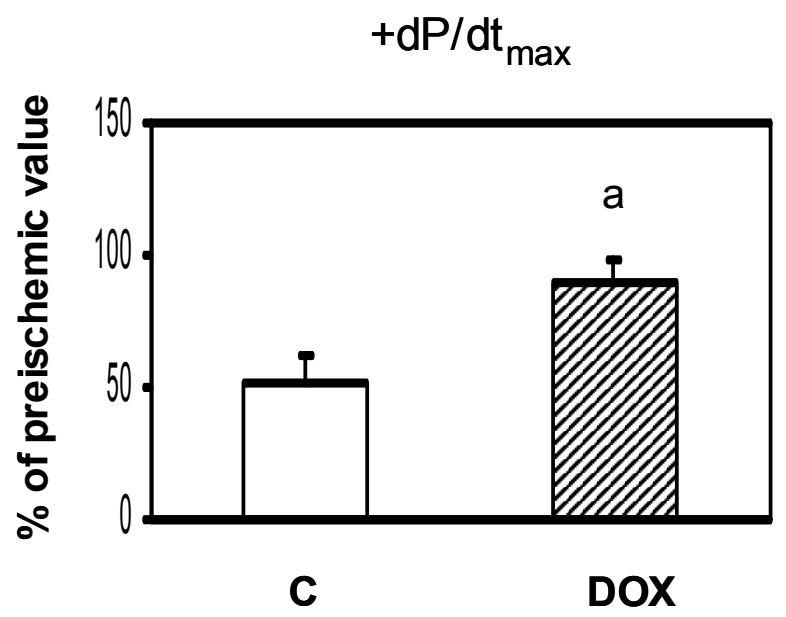

Fig. 1. Effect of DOX on the recovery of maximal rate of contraction ( $\left.+\mathrm{dP} / \mathrm{dt}_{\max }\right)$ after myocardial ischemia and reperfusion. Data are means \pm S.E.M expressed in $\%$ of baseline values. $\mathrm{C}$ - control rat hearts, DOX - doxorubicin-treated hearts, ${ }^{a} p<0.05$ vs. control.

\section{Statistical evaluation}

Quantification of protein levels was done using Phosphorimager Thyphoon (Amersham Biosciences). Data were expressed as means \pm S.E.M. Statistical significance of differences between the groups was analysed by the unpaired Student's t-test. Differences were considered as significant at $\mathrm{p}<0.05$.

\section{Results}

Six weeks after the first injection, the body weights were $266 \pm 25 \mathrm{~g}$ in the DOX-treated group and $278 \pm 23 \mathrm{~g}$ in the control group. The heart weight/ body weight ratio represented $0.313 \pm 0.010$ in the DOXtreated group and $0.317 \pm 0.020$ in the control group.

Effect of chronic doxorubicin treatment on postischemic recovery of contractile function in the rat heart

Figure 1 shows maximal recovery of contraction $+\mathrm{dP} / \mathrm{dtmax}$ after ischemia/reperfusion in control hearts and hearts of rats after chronic DOX treatment. In DOX-treated hearts significantly improved recovery of $+\mathrm{dP} / \mathrm{dtmax}$ after ischemia and reperfusion in comparison with control hearts has been observed. The data are expressed as percentage of preischaemic baseline values and represented $89.7 \pm 8.8 \%$ in DOXtreated hearts and $51.8 \pm 10.9 \%$ in control rat hearts. Recovery of left developed ventricular pressure (LVDP) after ischemia/reperfusion showed similar tendency of changes. In DOX-treated hearts the improved recovery of LVDP during whole reperfusion has been observed compared to its values in control hearts (data not shown).

Influence of chronic doxorubicin treatment on extracellular signal-regulated kinases (ERKs)

We did not observe significant differences in the levels of total ERKs between the control and DOXtreated rat hearts (Fig. 2A). However, using antibody that reacts specifically with dual phosphorylated ERKs (Thr202/Tyr204) we found that the exposure of rats to DOX was connected with significantly increased specific phosphorylation (activation) of both ERK-1 and ERK-2 (Fig. 2B-D).

\section{Effect of chronic doxorubicin treatment on p38-MAPK}

Analysis with antibody specific for p38-MAPK showed that there were not significantly influenced the levels of p38-MAPK in hearts of rats treated with doxorubicin. We also did not observe changes in phosphorylation of p38-MAPK on Thr180/Tyr182 (data not shown). Specific phosphorylation at these sites reflects the activation of $\mathrm{p} 38$-MAPK.

Influence of chronic doxorubicin treatment on levels and/or activation of heat stress proteins

Analysis of heat stress proteins showed changes in protein levels of HSP60 and HSP70. Using specific antibody we found that DOX treatment induced upregulation of the HSP60 levels in comparison with control hearts (Fig. 3). On the other hand, chronic treatment with DOX was associated with a downregulation of HSP70 expression (Fig. 4). For HSP90, we did not observe significant changes in content of this protein in rat hearts after DOX treatment. Analysis with phospho-specific antibody also did not show significant differences in specific Ser82 phosphorylation of HSP27 after chronic treatment with DOX (data not shown).

\section{Discussion}

In the present study we showed that rat hearts exposed to chronic doxorubicin (DOX) treatment show better recovery of contractile function after $I / R$. The investigation of changes associated with action of DOX revealed that prolonged exposure of rat hearts to DOX led to an activation of extracellular signal-regulated kinases and modulation of protein levels of HSP60 and HSP70. 
A

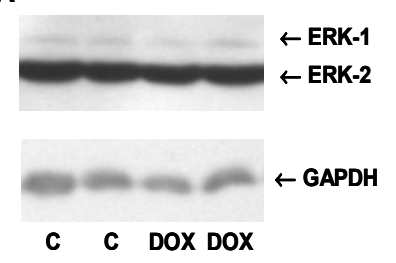

C

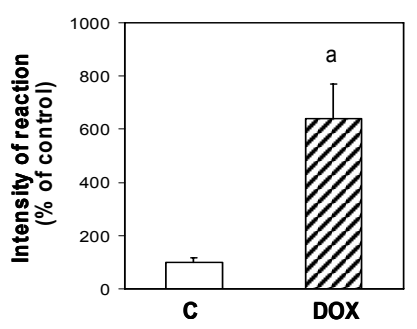

A

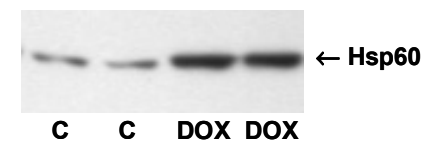

B

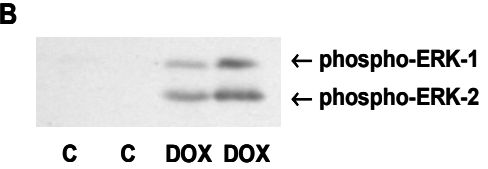

D

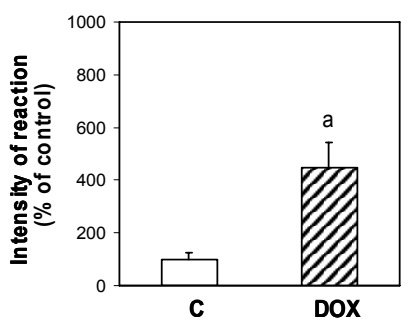

B

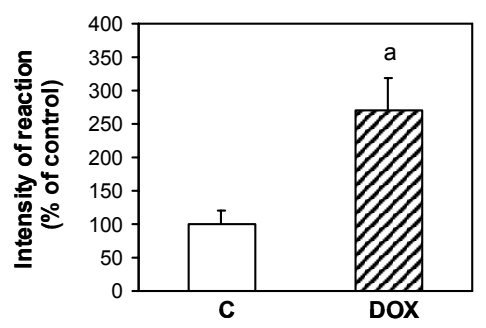

B

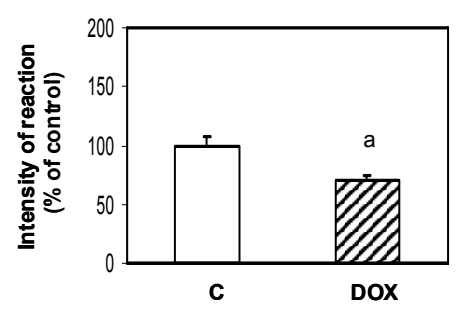

Fig. 2. Effect of chronic DOX treatment on protein levels and activation of extracellular signalregulated protein kinases (ERKs). A. Upper blot record shows ERKs levels in fractions isolated from the left ventricular tissue of control and DOXtreated rat hearts. The ERKs levels were determined using specific antibody. Blot in lower part shows the protein levels of GAPDH. B. The changes in specific phosphorylation of ERKs in control and DOX-treated rat hearts. The activation of ERKs was determined using phospho-specific antibody (Thr202/Tyr204). C. Quantification of phospho-ERK-1 content in the left ventricular tissue after DOX treatment. D. Quantification of phosphoERK-2 content in the left ventricular tissue after DOX treatment. Data are expressed as a percentage of values for control tissue. Each bar represents mean \pm S.E.M. of 5 tissue samples per group. ${ }^{a} p<0.05$ vs. control group. C - control hearts; DOX - doxorubicin-treated rat hearts.

Fig. 3. Effect of chronic DOX treatment on protein levels of HSP60. A. Record showing HSP60 protein levels in fractions isolated from the left ventricular tissue of control and DOX-treated rat hearts. The HSP60 levels were determined using specific antibody. B. Quantification of HSP60 content. Data are expressed as a percentage of values for control tissue. Each bar represents mean \pm S.E.M. of 5 tissue samples per group. ${ }^{a} p<0.05$ vs. control group. C - control rat hearts; DOX - doxorubicintreated hearts.

Fig. 4. Effect of chronic DOX treatment on protein levels of HSP70. A. Record showing HSP70 levels in protein fractions isolated from the left ventricular tissue of control and DOX-treated rat hearts. The HSP70 levels were determined using specific antibody. B. Quantification of Hsp70 content. Data are expressed as a percentage of values for control tissue. Each bar represents mean \pm S.E.M. of 5 tissue samples per group. ${ }^{a} p<0.05 \mathrm{vs}$. control group. C - control rat hearts; DOX- doxorubicintreated hearts.
DOX and its derivatives are used as chemotherapeutic drugs and it is known that long-term treatment with DOX can result in the development of cardiomyopathy and congestive heart failure. This involves multiple factors including the generation of free radicals, alterations in intracellular $\mathrm{Ca}^{2+}$ homeostasis, myocardial cell apoptosis (Kang et al. 2000, Singal et al. 2000). On the other hand, several cardioprotective substances are produced by the heart in response to the exposure of DOX which may attenuate cardiac injury. The exact mechanisms and biochemical pathways (events) that influence the cytotoxicity of DOX have not been well-characterized. Some studies have shown that cell growth and survival/death signaling pathways, PI3K/Akt and MAPKs pathways, play important roles in regulating DNA damage agents-induced cell death (Sawyer et al. 2002, Wang et al. 2002). We found that prolonged exposure of rats to DOX was connected with an increased activation of ERKs and this suggests their possible role in adaptive responses of myocardium to DOX treatment. The important role of ERK pathway in regulation of responses to DOX has been demonstrated in cultured rat neonatal cardiomyocytes (Arai et al. 2000). The authors found that DOX activated ERKs, p38MAPKs and SAPK/JNKs but only inhibition of ERK pathway suppressed the effects of DOX on SERCA2 
expression. The ERKs activation usually confers a survival advantage to cells and this indicates that the observed ERKs activation may play a role in adaptive responses that modulate doxorubicin-induced injury in the ischemic myocardium. Also in adult rat ventricular myocytes it has been shown that concerted activation of HER2, ERK1/2, and Akt serves as a salvage pathway against the damaging effects of DOX (Sawyer et al. 2002). Moreover, in a recent study it was found that DOX induced the activation of both caspase- 3 and Akt in the left ventricle, with the latter effect likely reflecting a protective response to counteract the induction of cardiomyocyte apoptosis (Ichihara et al. 2007). Doxorubicin-induced cytoxicity on cardiac cells was found to be prevented also by survival factors (IGF-1) acting through $\mathrm{PI} 3 \mathrm{~K} / \mathrm{Akt}$ kinase pathway (Wu et al. 2000). In contrast to ERKs, JNKs and p38-MAPK are thought to correlate with cardiomyocyte apoptosis and cardiac pathologies. DOX was also found to induce apoptosis by activating p38-MAPK and inhibitors of this kinase prevented DOX-induced apoptosis (Kang et al. 2000). We did not observe the effects of DOX on p38MAPK pathway. This was confirmed by the determination of p38-MAPK activation and also phosphorylation of HSP27. This small heat stress protein is a physiological substrate for MAPKAP kinase-2 which is activated by p38-MAPK. However, we did not observe changes in specific phosphorylation of HSP27 in response to DOX treatment. HSPs are essential for maintenance of normal cellular function and recovery after insult in essence acting as a chaperone, thereby preventing protein aggregation and participating in the refolding of damaged proteins following stress (Mayer and Bukau 1998). It was shown that these proteins could also play a role in modulation of apoptosis (Kim et al. 2006) and cell responses to DOX (Ohtsubo et al. 2000). We found different efects of DOX on expression of HSPs. The levels of HSP60 were up-regulated and the levels of HSP70 down-regulated in DOX-treated rat hearts. On the other hand, the HSP90 was not significantly influenced by the effect of DOX. The observed data suggest a link between HSP60 and HSP70 and cardiac function in hearts influenced by DOX. The connection between DOX and HSP60 was observed also in cardiomyocytes where it was found that overexpression of HSP60 significantly reduced DOXmediated induction of pro-apoptotic Bad protein (Shan et al. 2003). The influence of HSPs on activation of some protein kinases is also possible, and a recent study reported that the HSP90 inhibitor can reduce the phosphorylation of ERK without changing its total protein level. Furthermore, treating cells with HSP90 inhibitors decreased the protein level of Raf (Dou et al. 2005).

In conclusion, the data demonstrate the changes in signaling pathway of extracellular signal-regulated protein kinases and heat-stress proteins as a consequence of chronic treatment with doxorubicin. The latter might be potentially involved in the mechanisms underlying the modulation of cardiac functions.

\section{Conflict of Interest}

There is no conflict of interest.

\section{Acknowledgements}

Supported by VEGA SR grants No. 2/6170/26, 2/5110/25, APVV 51-027404, SP51/028 09 00/028 09 01.

\section{References}

ARAI M, YOGUCHI A, TAKIZAWA T, YOKOYAMA T, KANDA T, KURABAYASHI M, NAGAI R: Mechanism of doxorubicin-induced inhibition of sarcoplasmic reticulum $\mathrm{Ca}^{2+}$-ATPase gene transcription. Circ Res 86: 8-14, 2000.

BARANČÍK M, IVANOVÁ M, RAVINGEROVÁ T, BERNÁTOVÁ I: The role of protein kinases in responses to chronic social stress in rat hearts. Physiol Res 56: 4P, 2007.

BRADFORD M: A rapid and sensitive method for the quantitation of microgram quantities of protein utilizing the principle of protein-dye-binding. Anal Biochem 72: 248-254, 1976.

DOU F, YUAN LD, ZHU JJ: Heat shock protein 90 indirectly regulates ERK activity by affecting Raf protein metabolism. Acta Biochim Biophys Sin 37: 501-505, 2005.

FERRANS VJ: Overview of cardiac pathology in relation to anthracycline cardiotoxicity. Cancer Treat Rep 62: 955961, 1978. 
ICHIHARA S, YAMADA Y, KAWAI Y, OSAWA T, FURUHASHI K, DUAN Z, ICHIHARA G: Roles of oxidative stress and Akt signaling in doxorubicin cardiotoxicity. Biochem Bioph Res Commun 359: 27-33, 2007.

KANG JV, ZHOU ZX, WANG GW, BURIDI A, KLEIN JB: Suppression by metallothionein of doxorubicin-induced cardiomyocyte apoptosis through inhibition of $\mathrm{p} 38$ mitogen-activated protein kinases. J Biol Chem 275: 13690-13698, 2000.

KIM EK, PARK JD, SHIM SY, KIM HS, KIM BI, CHOI JH, KIM JE: Effect of chronic hypoxia on proliferation, apoptosis, and HSP70 expression in mouse bronchiolar epithelial cells. Physiol Res 55: 405-411, 2006.

KYRIAKIS JM, AVRUCH J. Sounding the alarm: protein kinase cascades activated by stress and inflammation. $J$ Biol Chem 271: 24313-24316, 1996.

MAYER MP, BUKAU B: Hsp70 chaperone systems: diversity of cellular functions and mechanism of action. Biol Chem 379: 261-268, 1998.

METTLER FP, YOUNG DM, WARD JM: Adriamycin-induced cardiotoxicity (cardiomyopathy and congestive heart failure) in rats. Cancer Res 37: 2705-2713, 1977.

OHTSUBO T, KANO E, UEDA K, MATSUMOTO H, SAITO T, HAYASHI S, HATASHITA M, JIN Z, SAITO H: Enhancement of heat-induced heat shock protein (hsp) 72 accumulation by doxorubicin (Dox) in vitro. Cancer Lett 159: 49-55, 2000.

SAWYER DB, ZUPPINGER C, MILLER TA, EPPENBERGER HM, SUTER TM: Modulation of anthracyclineinduced myofibrillar disarray in rat ventricular myocytes by neuregulin-1beta and anti-erbB2: potential mechanism for trastuzumab-induced cardiotoxicity. Circulation 105: 1551-1554, 2002.

SHAN YX, LIU TJ, SU HF, SAMSAMSHARIAT A, MESTRIL R, WANG PH: Hsp10 and Hsp60 modulate Bcl-2 family and mitochondria apoptosis signaling induced by doxorubicin in cardiac muscle cells. $\mathrm{J} \mathrm{Mol} \mathrm{Cell}$ Cardiol 35: 1135-1143, 2003.

SINGAL PK, DEALLY CMR, WEINBERG LE: Subcellular effects of adriamycin in the heart: A concise review. J Mol Cell Cardiol 19: 817-828, 1987.

SINGAL PK, LI T, KUMAR D, DANELISEN I, ILISKOVIC N: Adriamycin-induced heart failure: mechanism and modulation. Mol Cell Biochem 207: 77-86, 2000.

STRNISKOVÁ M, BARANČÍK M, NECKÁŘ J, RAVINGEROVÁ T: Mitogen-activated protein kinases in the acute diabetic myocardium. Mol Cell Biochem 249: 59-65, 2003.

SUGDEN PH, BOGOYEVITCH MA: Intracellular signalling through protein kinases in the heart. Cardiovasc Res 30: 478-492, 1995.

THORNALLEY PJ, DODD NJ: Free radical production from normal and adriamycin-treated rat cardiac sarcosomes. Biochem Pharmacol 34: 669-674, 1985.

WANG X, MARTINDALE JL, LIU Y, HOLBROOK NJ: The cellular response to oxidative stress: influences of mitogen-activated protein kinase signalling pathways on cell survival. Biochem J 333: 291-300, 1998.

WANG S, KOTAMRAJU S, KONOREV E, KALIVENDI S, JOSEPH J, KALYANARAMAN B: Activation of nuclear factor- $\mathrm{KB}$ during doxorubicin-induced apoptosis in endothelial cells and myocytes is pro-apoptotic: the role of hydrogen peroxide. Biochem J 367: 729-740, 2002.

WANG S, KONOREV EA, KOTAMRAJU S, JOSEPH J, KALIVENDI S, KALYANARAMAN B. Doxorubicin induces apoptosis in normal and tumor cells via distinctly different mechanisms. Intermediacy of $\mathrm{H}_{2} \mathrm{O}_{2}$ - and p53-dependent pathways. J Biol Chem 279: 25535-25543, 2004.

WU W, LEE WL, WU YY, CHEN D, LIU TJ, JANG A, SHARMA PM, WANG PH: Expression of constitutively active phosphatidylinositol-3-kinase inhibits activation of caspase 3 and apoptosis of cardiac muscle cells. J Biol Chem 275: 40113-40119, 2000. 